\title{
A PRODUÇÃO DO CUIDADO ÀS PESSOAS COM HANSENÍASE: UM OLHAR SOBRE A RESOLUBILIDADE DOS SERVIÇOS DE SAÚDE
}

\author{
Brenda Fadigas Carvalho'; Maria Yaná Guimarães Silva Freitas²; Fernanda Estrela ${ }^{3}$ e \\ Thalyne Pinheiro ${ }^{4}$ \\ 1. Bolsista PROBIC/UEFS, Graduanda em Enfermagem, Universidade Estadual de Feira de Santana, e-mail: \\ brendafadigas@gmail.com \\ 2. Orientadora, Departamento de Saúde, Universidade Estadual de Feira de Santana, Pesquisadora do Nupisc e-mail: \\ yana@uefs.br \\ 3. Participante do Núcleo de Pesquisa Integrado em Saúde Coletiva (NUPISC), Departamento de Saúde, Universidade \\ Estadual de Feira de Santana, e-mail: fernandaestrela1@gmail.com \\ 4. Participante do Núcleo de Pesquisa Integrado em Saúde Coletiva (NUPISC), Departamento de Saúde, Universidade \\ Estadual de Feira de Santana, e-mail: thalyne.sfpinheiro@gmail.com
}

PALAVRAS-CHAVE: Produção do Cuidado; Hanseníase; Resolubilidade.

\section{INTRODUÇÃO}

A produção do cuidado em saúde é vista como sistêmica e integrada aos demais níveis da assistência, através da utilização de todos os recursos disponíveis para a construção de um Projeto Terapêutico Singular (PTS) que atenda às necessidades da população (Merhy; Franco, 2005). Nesse contexto, a hanseníase é uma doença crônica, infectocontagiosa de evolução lenta, causada pelo Mycobacterium leprae, parasita que apresenta alta infectividade e baixa patogenicidade, e afeta primariamente os nervos periféricos e a pele, podendo causar sérias incapacidades físicas (ASSIS; JESUS, 2012). Já a resolubilidade é considerada como sendo uma resposta às demandas de acordo com as necessidades individuais e coletiva, garantindo ao usuário o acesso integral aos serviços de saúde (Santos; Assis, 2006). Essa pesquisa se justifica pelas lacunas de conhecimento sobre a temática, bem como a importância social do estudo da resolubilidade na produção do cuidado das pessoas com hanseníase, identificando as ações desenvolvidas de forma centralizada, na unidade de referência.

Diante disso, este estudo tem como questão norteadora: como ocorre a resolubilidade na produção do cuidado das pessoas com hanseníase no município de Feira de Santana- BA? Para responder tal questão, o estudo baseia-se no seguinte objetivo geral: analisar a resolubilidade na produção do cuidado executado pelo serviço de saúde às pessoas com diagnóstico de Hanseníase no município Feira de Santana-BA, além de ter como objetivos específicos: descrever as ações da equipe multidisciplinar no serviço de referência frente às demandas das pessoas com Hanseníase, em Feira de Santana-BA; compreender as facilidades e dificuldades para a resolubilidade na produção do cuidado das pessoas com Hanseníase, no serviço de referência, em Feira de Santana-BA.

\section{METODOLOGIA}

Estudo descritivo e exploratório de abordagem qualitativa, vinculado ao Projeto de Pesquisa, intitulado "Resolubilidade na Estratégia de Saúde da Família em dois cenários da Bahia, Brasil: processo de cuidar versus responsabilização da equipe e dos dirigentes do SUS.”, aprovado pelo Comitê de Ética em Pesquisa (CEP) da Universidade Estadual de Feira de Santana (UEFS), através do parecer de No 2010298.

Participaram da pesquisa profissionais que atuam no programa de referência para hanseníase no Centro de Saúde Especializado (CSE) Dr. Leone Coelho Lêda com. A coleta de dados foi realizada entre os meses de abril e maio de 2017, a partir do roteiro de entrevista semiestruturada e observação sistemática. Os dados coletados foram submetidos à análise de conteúdo de Bardin, sendo respeitadas as recomendações do Código de Ética em pesquisa 
com seres humanos, na Resolução 466/2012 do Conselho Nacional de Saúde durante todo o estudo.

\section{ANÁLISE E DISCUSSÃO DOS RESULTADOS}

Os oito entrevistados que participaram do estudo tinham idade entre 30 a 74 anos. Sete entrevistadas foram mulheres e apenas um homem. Quanto ao estado civil, seis pessoas estavam casadas, e as outras duas encontravam-se solteiras. Na avaliação da função que exercem no serviço foram entrevistados dois médicos, enfermeiros, técnicos em enfermagem, e fisioterapeutas. Já, em relação a escolaridade, sete pessoas declararam possuir o ensino superior completo, e uma possui apenas o curso técnico. No que se refere aos bairros, observou-se que os profissionais residem nas cinco regiões administrativas da sede do município (Feira de Santana, 2004).

Percebeu-se que os participantes atuam no serviço entre o período de anos que engloba dos três aos trezes anos. Em relação a carga horária seis entrevistados trabalham 30 horas semanais, já os outros dois, médicos, atuam no serviço duas vezes na semana com uma carga horária de 20 horas, e quanto ao vínculo sete profissionais trabalham por cooperativa, e uma é efetiva.

A partir dos dados coletados emergiram quatro categorias: Cumpre os protocolos ministeriais; Não se considera como equipe multiprofissional mesmo sendo unidade de referência; Dificuldades enfrentas no atendimento individualizado a pessoa com hanseníase; Estigma da doença infectocontagiosa.

Quanto ao cumprimento dos protocolos ministeriais foi observado, pelas falas dos profissionais que o atendimento a pessoa com hanseníase se dá de forma estruturada, em que a oferta e a assistência estão moduladas em conformidade com o Programa Nacional de Controle e Eliminação da Hanseníase (PNCEH).

O serviço opera com demanda espontânea ou através de encaminhamento por um profissional [...] A recepção faz a ficha do paciente, encaminha para a enfermagem, $e$ após a confirmação diagnóstica o paciente tem consulta com o médico e fisioterapeuta e inicia de imediato o tratamento de acordo com o tipo de hanseníase [..] É realizado o exame dos contatos próximos nos últimos cinco anos, e avaliada a necessidade de aplicar BCG, para fechar o bloqueio dos contactantes. Quando apresenta algum efeito colateral a medicação, ou reação hansênica, o paciente é encaminhado para avaliação médica e fisioterápica (Prof. 2).

Assis e Jesus (2012), estudaram que o acesso dos indivíduos com hanseníase nos serviços de saúde é garantido, pela demanda espontânea, ou por indicação de um profissional que tenha a suspeita da doença. Essa sistema, procura equilibrar a oferta em relação à demanda, buscando organizar a assistência e reduzir o tempo de espera para as consultas.

Evidenciou-se, durante o período de observação que o acesso às consultas no serviço de referência para hanseníase foi de responsabilidade da recepção da unidade, que utilizava como critério a ordem de chegada, para os atendimentos da enfermeira e fisioterapeutas, já em relação ao médico, a distribuição do número de vagas era limitada a 20 pessoas por dia de atendimento, seja no turno matutino ou vespertino.

Em relação, a falta de compreensão da equipe como sendo multiprofissional, os profissionais apesar de reconhecerem o papel desenvolvido por cada um no serviço, não visualizam a integração existente, e a importância do sucesso do cuidado produzido por cada elemento como garantia da melhora da assistência à pessoa com hanseníase.

$O$ atendimento a pessoa com hanseníase é feito aqui na unidade, cada profissional faz seu trabalho individualizado (Prof. 1).

A dificuldade em desenvolver o trabalho multiprofissional, em que todos visualizem a importância do seu papel, está fundamentada no desconhecimento sobre a concepção da transdisciplinaridade, ou seja, na articulação dos saberes, promovida pela comunicação e 
estudo entre todos que compõe o serviço, na constituição de uma assistência unificada e não dissociada (Moraes; Paes, 2016).

Ademais, as dificuldades enfrentas no atendimento individualizado a pessoa com hanseníase, estão relacionadas a prática da assistência articulada apenas para o cumprimento de protocolos, a alta demanda do serviço, e falta de recursos materiais, que corroboram para o desenvolvimento de uma assistência desassociada à proposta do PTS.

Todos são atendidos de maneira igual, sem diferenças. A infraestrura da unidade é antiga, e precisa de reparos. Em relação aos outros profissionais, poderia ter um psicólogo, neurologista, infectologista, e um médico cirurgião de pequenas cirurgias para que colha a biópsia para que faça aqui no programa, porque temos paciente que demora muitos meses 3 a 4 meses (Prof. 7).

Lanza, Lana (2011), consideram que a manutenção do modelo vertical de atendimento a pessoa com hanseníase não favorece o acesso da população ao diagnóstico e tratamento na fase inicial da doença, e também dificulta a busca ativa, de contatos, ações educativas, e tratamento especializado para cada indivíduo, porque o padrão de atenção à saúde centralizado, corrobora para o desenvolvimento de práticas protocoladas pelos manuais, sem levar em consideração o contexto social da patologia.

Todavia, a alta demanda dos serviços de média complexidade e sua relação com a necessidade de ampliar a equipe de saúde como alternativa para resolver os problemas existentes, está relacionada a descaracterização do serviço primário pelo usuário, que corrobora na sobrecarga de trabalho, e dificuldade em promover uma assistência mais especializada e focada nas particularidades individuais (Barbosa et al. 2008).

Além da dificuldade em desenvolver uma assistência integral a pessoa com hanseníase, pela verticalização do atendimento, associado a demanda da unidade, e dificuldades em conseguir a integração entre os serviços de saúde, também existe a falta de recursos materiais e estruturais no serviço de referência, pois observou-se que a unidade de referência apesar de estar estruturada para atender usuário, a mesma possui equipamentos antigos, e não há espaço adequado para a realização de atividades educativas e de fisioterapia, além da falta de maior conforto para as pessoas.

Weirich et al. 2009, considera que a falta de insumos materiais aos usuários dos serviços de saúde, é também configurada como uma barreira a resolubilidade, uma vez que torna o atendimento inadequado, gerando a insatisfação do usuário, sobrecarga e estresse da equipe de saúde com a queda do rendimento, acarretando em desgaste para os profissionais

Também, os profissionais sinalizam a continuidade do estigma e preconceito em relação a pessoa com hanseníase na sociedade, mesmo com a veiculação de informações na mídia, sobre o seu tratamento e cura.

O estigma e preconceito dessa doença é muito grande, que as pessoas acabam abandonando o tratamento e nós perdemos o contato, até que ela resolva retornar ao serviço (Prof. 5).

Cid et al. (2012), considera que o estigma existe principalmente devido à carência de conhecimento da população sobre a doença, que do ponto de vista médico tem tratamento e cura, mas principalmente pelo preconceito criado na antiguidade, corrobora para a exclusão social das pessoas, afetando sua autoestima, saúde emocional e psicológica.

\section{CONSIDERAÇÕES FINAIS}

Neste estudo, vimos que a produção do cuidado à pessoa com hanseníase realizada em um centro de referência, está relacionada ao trabalho desenvolvido por uma equipe multiprofissional composta por: médicos, equipe de enfermagem, fisioterapeutas, assistente social.

A existência de uma assistência de referência voltada apenas para a organização do serviço e não para quem lhe é destinada, contribui para a fragmentação da assistência, e 
dificulta o desenvolvimento de ações em equipe, uma vez que nessa unidade, o trabalho desenvolvido está voltado apenas para cumprimento do protocolo, e as atividades são desenvolvidas de forma desarticulada, por isso é necessário a promoção do trabalho transdisciplinar, ou seja, a articulação dos saberes da equipe, na constituição de uma assistência voltada para o desenvolvimento da clínica ampliada e do PTS.

Deve-se fortalecer as redes de assistência municipal para que os exames e necessidades de outros profissionais sejam mais eficazes, ágeis, e resolutivos.

No que se se refere ao estigma existente acerca da hanseníase, percebemos que a sociedade, muitas vezes, exclui e inferioriza o indivíduo, pois acredita que, assim, está protegida do contato com o Mycobacterium leprae, mas em contra partida não percebe que o estigma acarreta na demora do tratamento e dificulta a interrupção da cadeia de transmissão.

Os resultados do estudo poderão contribuir para pesquisas futuras com outras metodologias e que tenham como análise as mudanças associadas a descentralização do atendimento da hanseníase como alternativa para o desenvolvimento da humanização da assistência, a fim de avaliar a sua resolutividade.

\section{REFERÊNCIAS}

ASSIS, M.M.A; JESUS, W.L.A. 2012 [online]. Acesso aos serviços de saúde: abordagens, conceitos, políticas e modelo de análise. Ciência e Saúde Coletiva. 17 (11): 2865-2875. Homepage:// http://www.scielo.br/pdf/csc/v17n11/v17n11a02.pdf.

BARBOSA, J.C et al. 2008 [online]. Olhares sobre as ações do programa de controle da hanseníase: a perspectiva dos profissionais de saúde no Brasil. Caderno de Saúde Coletiva. 16(2):273-292. Rio de Janeiro. Homepage://http://www.cadernos.iesc.ufrj.br/cadernos/images/csc/2008_2/artigos/CSC_IESC _2008_2_10.pdf.

CID, R.D.S et al. 2012 [online]. Percepção de usuários sobre o preconceito da hanseníase. Revista da Rede de Enfermagem do Nordeste. 13 (5): 10041014.Homepage://http://www.revistarene.ufc.br/revista/index.php/revista/article/viewFile/115 8/pdf.

FEIRA DE SANTANA, 2004 [online]. Lei $n^{\circ}$ 1.631/95, Lei complementar 018/2004. Feira de Santana. Homepage://https://leismunicipais.com.br/legislacao-municipal/328/leis-de-feira-desantana.

LANZA, F.M; LANA, F.C.F.2011 [online]. Descentralização das ações de controle da hanseníase na microrregião de Almenara, Minas Gerais. Revista Latino-Americana de Enfermagem, 19 (1): 8. Homepage://http://www.scielo.br/pdf/rlae/v19n1/pt_25.

MERHY, E.E; FRANCO, T.B. 2005. A Produção Imaginária da Demanda e O Processo de Trabalho em Saúde in Pinheiro, R. \& Mattos, R.A. (orgs.) "Construção Social da Demanda"; IMS/UERJ-CEPESC-ABRASCO, Rio de Janeiro.

MORAES, I.C.D; PAES, I.A.D.C. 2016 [online]. Percepções de uma equipe multiprofissional atuante no programa saúde na escola. Revista Científica da FHO UNIARARAS. 4 (1)1- 9. Homepage://http://www.uniararas.br/revistacientifica.

SANTOS, A. M; ASSIS, M. M. A. 2006 [online]. Da fragmentação à integralidade: construindo e (des)construindo a prática de saúde bucal no Programa de Saúde da Família (PSF) de Alagoinhas, BA. Ciência e saúde coletiva.11 (1): 53-61. Rio de Janeiro. Homepage:// http://www.scielo.br/pdf/csc/v11n1/29448.pdf.

WEIRICH, C. F et al. 2009 [online]. O trabalho gerencial do enfermeiro na rede básica de saúde. Texto Contexto Enfermagem. 18 (2): 249-57. Florianópolis. Homepage://http://www.scielo.br/pdf/tce/v18n2/07. 